\title{
Influence of CYP450 enzymes, CES1, PON1, ABCB1 and P2RY12 polymorphisms on clopidogrel response in patients subjected to a percutaneous neurointervention procedure
}

\author{
Miriam Saiz-Rodríguez ${ }^{1}$, Carmen Belmonte ${ }^{1,2}$, José Luis Caniego ${ }^{3}$, Dora Koller ${ }^{1}$, Pablo \\ Zubiaur $^{1}$, Eduardo Bárcena ${ }^{3}$, Daniel Romero-Palacián ${ }^{1}$, Andy Eugene $^{4}$, Dolores Ochoa ${ }^{1,2}$, \\ Francisco Abad-Santos ${ }^{1,2,5}$.
}

${ }^{1}$ Clinical Pharmacology Department, Hospital Universitario de la Princesa, Instituto Teófilo Hernando, Universidad Autónoma de Madrid (UAM), Instituto de Investigación Sanitaria la Princesa (IP), Madrid, Spain

${ }^{2}$ UICEC Hospital Universitario de la Princesa, Plataforma SCReN (Spanish Clinical Reseach Network), Instituto de Investigación Sanitaria la Princesa (IP), Madrid, Spain.

${ }^{3}$ Department of Radiology, Hospital Universitario de la Princesa, Universidad Autónoma de Madrid (UAM), Madrid, Spain

${ }^{4}$ Independent Research, Larned, KS, USA; Independent Neurophysiology Laboratory, Department of Psychiatry, Medical University of Lublin, Lublin, Poland.

${ }^{5}$ Pharmacology Department, Facultad de Medicina, Universidad Autónoma de Madrid, Madrid, Spain

\section{CORRESPONDING AUTHOR}

Dr. Francisco Abad Santos

Clinical Pharmacology Department, Hospital Universitario de la Princesa

Diego de León 62. 28006 Madrid, Spain

Tel: 34 915202425; Fax: 34915202540

E-mail: francisco.abad@salud.madrid.org

\section{CONFLICT OF INTERESTS}

F. Abad-Santos has been consultant or investigator in clinical trials sponsored by the following pharmaceutical companies: Abbott, Alter, Chemo, Cinfa, FAES, Farmalíder, Ferrer, GlaxoSmithKline, Galenicum, Gilead, Janssen-Cilag, Kern, Normon, Novartis, Servier, Silverpharma, Teva, and Zambon. The remaining authors declare no conflicts of interest.

\section{SOURCE OF FUNDING}

The MassArray genotyping service was carried out at CEGEN-PRB3-ISCIII; it is supported by grant PT17/0019, of the PE I+D+i 2013-2016, funded by ISCIII and ERDF. 


\section{INTRODUCTION}

Clopidogrel is one of the most used agents in the perioperative management of patients undergoing neurointerventional procedures. It is a thienopyridine prodrug usually given in combination with acetylsalicylic acid to prevent atherothrombotic and thromboembolic events (1).

Clopidogrel absorption is mainly limited by P-glycoprotein (P-gp) (2), encoded by $A B C B 1$, an ATP-dependent transporter located in the intestinal epithelial cell wall which expels the drug into the intestinal lumen. Afterwards, clopidogrel is extensively metabolized in the liver. Most of the parent drug (approximately $85 \%$ ) is metabolized to its inactive form (carboxylic acid) by carboxylesterase 1 (CES1) (3). The remaining (15\%) suffers two sequential oxidative stages, through several cytochrome P450 (CYP) enzymes, originating the active metabolite. First, CYP2C19, CYP2B6 and CYP1A2 isoforms convert clopidogrel to 2-oxo-clopidogrel. Second, CYP3A4, CYP3A5, CYP2B6, CYP2C9 and CYP2C19 isoforms and the enzyme paraoxonase-1 (PON1) transform 2-oxo-clopidogrel into its active form $(4,5)$. Besides, $50 \%$ of the formed 2oxo-clopidogrel is also metabolized by CES1 to an inactive compound, consequently, limiting the amount of active metabolite (6). The active metabolite contains a thiol group which binds irreversibly to platelet $\mathrm{P} 2 \mathrm{Y}_{12}$ receptors, thereby inhibiting platelet activation and aggregation (7).

Several studies have evaluated the influence of CYP2C19 polymorphisms on clopidogrel effect. The presence of CYP2C19 intermediate metabolizer (IM) and poor metabolizer (PM) phenotypes has been associated with a hyporesponsiveness to clopidogrel, since they show lower levels of the active metabolite. Therefore, carriers of these variants have a higher risk of recurrent vascular events (8-11). On the other hand, carriers of CYP2C19 ultra-rapid metabolizer (UM) phenotype could show greater platelet inhibition and a hyperresponsiveness to clopidogrel (12-15), and consequently, an increased risk of hemorrhagic complications $(10,16,17)$. With this respect, the Clinical Pharmacogenetics Implementation Consortium (CPIC) made a series of therapeutic recommendations based on CYP2C19 genotype for the treatment of acute coronary syndromes with clopidogrel (18).

Regarding neurovascular conditions, there is no genotype-guided therapeutic recommendation. Our group has previously described an association between the IM-PM phenotype and a hyporesponse to clopidogrel, along with a significantly higher rate of hemorrhagic events in UM patients undergoing a percutaneous neurointervention (19). In the 
current study, our aim is to evaluate the effect of other genes involved in clopidogrel absorption and metabolism in this cohort of patients, including 21 new cases. This knowledge is of great importance to ensure the correct antiaggregation of these patients and to avoid as far as possible the risk of subsequent events.

\section{RESULTS}

Patient characteristics

Our study population comprised 144 patients ( 74 men and 70 women). Table 1 shows their main demographic characteristics. $46.5 \%$ of the patients were intervened due to the presence of an aneurysm and $51.4 \%$ presented a stenosis. Aneurysms were more frequently found in women; while stenosis was more frequently detected in men.

The genotype frequencies are shown in supplementary table 2 . There was no difference in the distribution of genotype frequencies among sexes, except for CYP1A2*1C in which all the carriers were women $(p=0.025)$, and $C Y P 1 A 2 * 1 B$ in which more women carried the $* 1 /{ }^{*} 1$ genotype $(32.4 \%)$ than men (13.9\%), $p=0.034$.

\section{Patient outcome}

The mean aggregation value (measured in 141 of the patients) was $161.3 \pm 87.3$ PRU. Men showed higher aggregation value (173.8 \pm 86.0 PRU) than women (148.1 \pm 87.3 PRU), although it was not significant ( $p=0.081$ ) (table 1 ). According to this parameter, $56 \%$ of the patients were categorized into responders, being this percentage higher in women (64\%) than in men (49\%), $p=0.090$. In all, $5 \%$ of the patients required a dose reduction $(8.6 \%$ of women and $1.4 \%$ of men, $p=0.058$ ), while $14 \%$ required a change of treatment. The median treatment duration was 80 days, with a range of 1-3079 days.

Regarding the primary outcome, $18.8 \%$ of the patients experienced a clinical event. The incidence of ischemic events was higher (10.4\%) than the incidence of hemorrhagic events (8.3\%), with no significantly different distribution among sexes. During the neurointerventional procedures, 4 patients experienced a hemorrhage due to a perforation of an artery. Two of them were CYP2C19 IM-PM, one was CYP2C19 NM and another one was CYP2C19 UM. These hemorrhages were not considered in the analysis since they were not related to clopidogrel 
treatment but related to the procedure. Table 2 shows a summary of the patients' outcome according to the different genotypes/phenotypes of the genes analyzed.

\section{Influence of CYP2C19 on patient outcome}

CYP2C19 clearly had an influence on the patients' outcome. CYP2C19 IM-PM patients showed a significantly higher aggregation value, which led to a significant worse response to clopidogrel (table 2). This lack of response may explain a significant shorter treatment duration (non-standardized $\beta$ coefficient $=-235.6 ; p=0.027$ ) in these patients.

Moreover, regarding the primary outcome, the incidence of ischemic events was lower in the UM group (2.3\%) compared to IM-PM (10.8\%) and NM (15.9\%), $p=0.060$. Figure 1a shows the time until appearance of an ischemic event, with a significant difference between the survival functions of the three phenotypes $(p=0.043)$. The comparison by pairs with Statistical Log-Rank did not detect significant differences in IM-PM compared to NM $(p=0.996)$ and IM-PM compared to UM ( $p=0.076)$; while there was a difference in UM compared to NM $(p=0.017)$. Moreover, Haberman-corrected typed residues pointed to a significant lower frequency of ischemic events in the UM group (2.3\%) than the expected under the hypothesis of independence between variables (9.7\%); while the frequency of ischemic events in NM (15.9\%) was not significantly higher compared to the expected.

The highest incidence of hemorrhagic events was detected in the UM group (15.9\%) compared to NM (6.3\%) and IM-PM (2.7\%), although this difference did not reach statistical significance $(p=0.101)$. The hemorrhagic events onset time is shown in figure $1 b$, showing a difference between the survival functions of the three phenotypes $(p=0.041)$. However, the comparison by pairs with statistical log-rank did not detect significant differences: IM-PM compared to NM $p=0.547 ; \mathrm{IM}-\mathrm{PM}$ compared to $\mathrm{UM}: \mathrm{p}=0.078$; $N M$ compared to $\mathrm{UM}: \mathrm{p}=0.097$. Nevertheless, Haberman-corrected typed residues showed a significantly higher frequency of hemorrhagic events in the UM group (15.9\%) than expected (8.3\%); while the frequencies observed in the IM-PM and NM groups did not differ significantly from the expected under the hypothesis of independence between variables.

Influence of other CYP enzymes, CES1 and PON1 enzymes on patient outcome

There was no influence of CYP2C9, CYP2C8, CYP1A2, CYP2B6, CYP3A4 and CYP3A5 on the aggregation value (table 2 ). 
Concerning CES1, although it did not reach statistical significance, we observed that patients carrying the C/T genotype of rs71647871 showed a considerable lower aggregation value (59.0 $\pm 21.2 \mathrm{PRU})$ compared to the wild-type genotype (165.2 $\pm 86.0 \mathrm{PRU}), \mathrm{p}=0.084$. There was no influence of PON1 enzyme on the aggregation value.

Regarding the primary outcome, the incidence of ischemic events was higher in the CYP2C9 PM-IM phenotype (15.9\%) compared to NM (5.6\%), but it was not statistically significant $(p=0.059)$. Nevertheless, neither other CYP enzyme, CES1 nor PON1 had a significant influence on the incidence of ischemic or hemorrhagic subsequent events.

\section{Influence of $A B C B 1$ on patient outcome}

There was a tendency towards a lower aggregation value in patients carrying the mutated alleles of $A B C B 1$ C3435T, C1236T and G2677T/A. In fact, the percentage of responders was significantly higher in patients carrying the mutated haplotype (table 2). However, there was no association between $A B C B 1$ haplotypes and the incidence of ischemic or hemorrhagic events.

\section{Influence of P2RY12 on patient outcome}

Neither individual polymorphisms nor P2RY12 haplotypes $\mathrm{H} 1$ and H2, including rs10935838, rs2046934, rs5853517 and rs6809699, had no influence on the aggregation value. Likewise, there was no association between P2RY12 polymorphisms and the incidence of ischemic or hemorrhagic events.

\section{Influence of the concomitant treatment with proton-pump inhibitors}

In all, $76.4 \%$ of the patients were receiving proton-pump inhibitors (PPIs) as a concomitant treatment, which are CYP2C19 inhibitors. Of them, 50\% were receiving omeprazole and $50 \%$ pantoprazole. Patients under PPIs treatment showed a significantly higher aggregation value (170.7 \pm 84.5 PRU) compared to those without PPIs treatment (129.0 \pm 90.2 PRU), $p=0.017$. Moreover, both patients receiving omeprazole and pantoprazole showed similar aggregation value (170.8 \pm 84.1 PRU and $170.6 \pm 85.8 \mathrm{PRU}$, respectively). However, there was no influence of the concomitant treatment with PPIs on the incidence of both ischemic $(10.9 \%$ of patients receiving PPIs vs. $8.8 \%$ of patients not receiving PPIs, $p=0.768)$ and hemorrhagic events $(9.1 \%$ of patients receiving PPIs vs. $5.9 \%$ of patients not receiving PPIs, $p=0.732$ ). 
Results from the multivariate analysis

A multiple regression analysis was performed considering the aggregation value, the response rate, the incidence of ischemic and hemorrhagic events as dependent variables. It included sex, age, all the genes analyzed, presence of cardiovascular risk factor (hypertension, dyslipidemia, obesity, atrial fibrillation, diabetes mellitus, current smoker), previous ischemic of hemorrhagic events, type of intervention and concomitant treatment with PPIs as independent variables. A summary of the results is shown in table 3.

Briefly, age, PPIs concomitant treatment and CYP2C19 IM-PM phenotype appeared to be predictors of a worse response due to a higher aggregation value. Besides, being intervened with a flow diverter was a predictor of a better response, compared to stent and coils intervention. This four factors explained the $26.4 \%$ of the model variance $\left(r^{2}=0.327\right)$. When transforming the aggregation value into a categorical variable, we observed that age and CYP2C19 IM-PM continued to be worse response predictors. Additionally, ABCB1 mutated haplotype appeared as a predictor of a better response $\left(r^{2}=0.433\right)$.

In addition, as shown in table 3, CYP2C19 UM phenotype was a protective factor while the treatment duration was a risk factor for the development of ischemia. Regarding the prediction of hemorrhagic events, CYP2C19 UM appeared to be the only risk factor.

\section{DISCUSSION}

The variability related to clopidogrel response is a well-known aspect, since a range of $4-30 \%$ of the patients are non-responders (20). Therefore, these patients are at increased risk of ischemic events after stent implantation (21). Factors such as age, body mass index, comorbidities, concomitant treatment, and compliance explain less than $10 \%$ of this variability (22). Consequently, the role genetics play could be of great importance.

\section{Influence of CYP2C19}

According to the expected, we found that CYP2C19 UM phenotype is a protective factor for the development of ischemic events, which was already observed in our previous work (23). Our results contradict those of Lin et al., who found that carriage of CYP2C19*17 allele was associated with the incidence of ischemic events (24). In fact, we already showed an increased risk of bleeding in CYP2C19 UM patients $(19,23)$, which Haberman-corrected typed residues confirmed in the current study with a larger sample size. We encourage considering this fact for the treatment approach of these patients. 
Furthermore, Zhu et al. established a correlation between CYP2C19 no function alleles and an increased risk of subsequent ischemic events in patients subjected to a stent implantation in the carotid artery (25). However, in our study, we could not confirm this fact, probably due to the small sample size. Moreover, carriers of CYP2C19*2 allele are more closely evaluated. In fact, after the vast amount of evidence, most clinicians decide to change clopidogrel for an alternative therapy to avoid the risk of subsequent events. Conversely, what we could confirm is the premise by Colley and Yan, who published a revision about the association between the carriage of CYP2C19*2 allele and a hyporesponse to clopidogrel in neurointervened patients (1). This circumstance was already observed in our previous work with a lower sample size (19).

Besides, Moore et al. compared the efficacy, safety and cost of the treatment with clopidogrel vs. ticagrelor in patients with cerebral aneurysms treated with flow diverter. They found that ticagrelor was not inferior when preventing thromboembolic complications. However, due to the much higher costs of ticagrelor, this alternative therapy should be used only in clopidogrel non-responders (26). Based on our results, we suggest that both CYP2C19 IM-PM and UM should be given an alternative antiplatelet therapy.

\section{Influence of other CYP enzymes, CES1 and PON1}

There is controversy whether there is an association of CYP2C9 most studied alleles $(* 2$ and *3) and clopidogrel effect. Some authors state no significant relationship (12) while others associate the presence of $* 3$ allele with a higher incidence of stent thrombosis (27). In our study CYP2C8 or CYP2C9 were not associated with a difference in clopidogrel response. However, we observed a tendency towards a higher incidence of ischemic events in subjects carrying CYP2C8 or CYP2C9 PM- IM phenotype, which was not statistically significant neither in univariate nor multivariate analyses. Further approaches with larger sample sizes would be of interest.

Reduced CYP3A4 activity has been associated with an increased risk of stent thrombosis in patients with acute coronary syndrome treated with clopidogrel (28). Indeed, one study postulates that the role of CYP3A4/5 in the metabolism of clopidogrel may be of greater relevance than has been previously described (29). However, in our study, CYP3A4 and CYP3A5 did not show a significant role in explaining some of the response variability. Our results resembled those of Holmberg et al. who found that neither CYP3A4 nor CYP3A5 genotypes 
affected clopidogrel area under the concentration-time curve or platelet inhibition in healthy volunteers (30).

Furthermore, the G143E polymorphism (rs71647871) described in CES1 was associated with a decreased protein functionality (31). Lewis et al. found that carriers of the mutated allele showed higher levels of the active metabolite and, therefore, a better response to clopidogrel in patients with coronary disease (32). Consistent with these studies, we have found a tendency towards a lower aggregation value in patients carrying the mutation, which can be explained by an increased active metabolite formation due to a lower CES1 functionality. However, our limited sample size was not sufficient to find statistically significant results, since we could only find two carriers of the G143E polymorphism. Further research is needed in this cohort of patients to confirm if there is an association.

Regarding PON1, it has been described that the Q192R polymorphism (rs662) conditions the active metabolite formation (5). In our study, we observed that patients carrying defective PON1 alleles, assigned as PM and IM, showed a tendency towards a higher aggregation value, although it was far from significance. This fact is consistent with the previously reported by Verschuren et al, who found that patients carrying the defective allele of rs662 may have lower levels of the active metabolite, thus resulting in a poorer response and an increased risk of ischemic events (33). In our study, the incidence of ischemic events was higher in the PM group. Further research is warranted.

\section{Influence of $A B C B 1$}

Taubert et al. described lower levels of clopidogrel and its metabolite in patients carrying the ABCB1 C3435T T/T genotype, probably due to an increased expression of P-gp (2). Conversely, our results suggest that patients carrying the C3435T, C1236T or G2677T/A minor alleles have a reduced $\mathrm{P}$-gp expression, since we found a better response prediction in patients carrying the $A B C B 1$ mutated haplotype. This would be explained by higher concentrations of clopidogrel and its metabolite, since the efflux pump would be working inefficiently. Some studies relate the most studied $A B C B 1$ polymorphism, C3435T, to a lower P-gp expression in minor allele carriers (34-37). Indeed, if the minor alleles are associated with reduced transporter functionality, it is expected that these patients show higher concentrations of P-gp substrate drugs, as a result of a minor elimination. For this reason, clopidogrel absorption might be influenced by $A B C B 1$ polymorphisms. 
Influence of P2RY12

Finally, as $P 2 R Y 12$ is the gene encoding for clopidogrel target receptor P2Y12, some polymorphisms (rs10935838, rs2046934, rs5853517 and rs6809699) have been associated with enhanced platelet reactivity $(38,39)$. However, these associations were not replicated and the level of evidence is low. In our study, we could not find a significant association in P2RY12 haplotypes related to clopidogrel response. The lack of association between P2RY12 polymorphisms and clopidogrel response match the results from Giusti et al. (9) and Cuisset et al. (40). They demonstrated that P2RY12 rs2046934 polymorphism was not associated with antiplatelet activity in patients with acute coronary syndrome treated with clopidogrel. Moreover, Simon et al. described no association between rs16846673, rs6809699 and rs6785930 and risk of adverse cardiovascular events in patients with acute myocardial infarction receiving clopidogrel (41).

\section{STUDY LIMITATIONS}

Our main limitation is our unfeasibility of measuring clopidogrel and its active metabolite concentrations, which could have been useful to correlate it with patients' aggregation value and clinical outcome. Moreover, the small sample size limited us from finding more patients carrying some minor alleles with a low frequency that might be related to clopidogrel metabolism, like CES1 polymorphisms. Hence, further investigation is warranted.

\section{CONCLUSION}

We confirmed that CYP2C19 is the most important enzyme involved in clopidogrel response. Indeed, the carriage of CYP2C19*2 allele is strongly associated with a hyporesponse to clopidogrel in neurointervened patients. Carrying the CYP2C19*17 allele is a protective factor for the development of ischemic events, while it is a risk factor for bleeding complications. An alternative therapy should be prescribed for CYP2C19*2 carriers but also for patients carrying CYP2C19*17 allele, to avoid bleeding complications. Moreover, we found a lower aggregation value in $A B C B 1$ mutated patients, being this haplotype a predictor of a better response, finding clopidogrel absorption clearly influenced by P-glycoprotein. Patients carrying the CES1 G143E $\mathrm{C} / \mathrm{T}$ genotype showed a considerable lower aggregation value, although not significant, which suggest an increased active metabolite formation. To date, the influence of polymorphisms in other CYP enzymes, CES1, PON1 or P2RY12 is not demonstrated in patients subjected to neurointervention procedures, further research is needed. 


\section{MATERIALS AND METHODS}

\section{Study population, design and procedures}

This retrospective observational study analyzed the clinical data of patients subjected to percutaneous neurointervention who were treated with clopidogrel. We included 144 patients from May 2013 to October 2018. The primary safety endpoint was the incidence of either thrombotic or hemorrhagic events during the treatment with clopidogrel, which could vary from a few days to several months. Other endpoints included: antiplatelet response, requirement of dose reduction, change of the antiplatelet therapy and treatment duration. All the data was collected from the medical records and included demographic factors (age and sex), cardiovascular risk factors (such as smoking status, hypertension, dyslipidemia, obesity, diabetes mellitus, chronic obstructive pulmonary disease, atrial fibrillation, acute myocardial infarction or previous ischemic and hemorrhagic events), and type of intervention. Concomitant treatment with CYP2C19 inhibitors was also taken into account.

This study complied with Declaration of Helsinki and current Spanish legislation on clinical research in humans and was approved by the Ethics Committee of Drug Research of Hospital Universitario de La Princesa.

\section{Antiplatelet response}

Antiplatelet response was documented with the VerifyNow System (Accriva Diagnostics, San Diego, CA), which determine the level of platelet P2Y12 receptor blockade (PRU - P2Y12 Reaction Unit) by determining the adenosine diphosphate (ADP) induced aggregation (extent of platelet aggregation in the presence of P2Y12 inhibitors). Platelet reactivity tests were performed prior to the intervention was accomplished. Values below 180 PRU suggest evidence of a P2Y12 inhibitor effect while values over 180 PRU suggest that there is no drug effect due to low P2Y12 inhibition response. Based on these values we classified the patients into responders to clopidogrel (values below 180 PRU) and non-responders (values over 180 PRU), according to the Verify Now Reference Guide (Accriva Diagnostics, San Diego, CA). Clopidogrel dose was adjusted according to hyper- or hypotreatment response.

\section{Genotyping}

DNA was extracted from $1 \mathrm{~mL}$ of peripheral blood samples using MagNA Pure LC DNA Isolation Kit in an automatic DNA extractor (MagNa Pure ${ }^{\circledR}$ System, Roche Applied Science, Indianapolis, Indiana) and quantified spectrophotometrically in a NanoDrop ${ }^{\circledR}$ ND-1000 Spectrophotometer 
(NanoDrop Technologies Inc, Wilmington, Delaware), the purity of the samples was measured by the $A_{260} / 280$ absorbance ratio.

We analyzed 34 polymorphisms in 11 genes related to clopidogrel metabolism, transport and mechanism of action. A complete list of the analyzed variants and their functional consequences is described in Suplemmentary table 1.

CYP2C19*2, *3 and $* 17$ genotyping was performed by real-time polymerase chain reaction (qPCR) with hybridization probes, designed and manufactured by TIB MOLBIOL (Berlín, Germany) in a LightCycler 2.0 device (Roche Bioscience, Mannheim, Germany), as previously described (19). Of the 144 samples genotyped for CYP2C19 variants, only 140 were available for genotyping the rest of the polymorphisms. CYP1A2*1C (rs2069514), CYP2B6*9 (rs3745274) and PON1 rs705379 were genotyped by qPCR using a StepOne ${ }^{\circledR}$ PCR Instrument (Applied Biosystems, CA, USA) and TaqMan assays following the manufacturer recommendations (Applied Biosystems, CA, USA). The genotyping of ABCB1, CYP1A2 (*1F and *1B), CYP2B6*5, CYP2C8, CYP2C9, CYP3A4, CYP3A5, PON1, CES1, P2RY12, UGT1A1, UGT2B7 and UGT2B4 was performed by MALDI-TOF mass spectrometry, with the MassARRAY ${ }^{\circledR}$ platform (Agena Bioscience Inc., San Diego, CA, USA). All assays were performed with an internal quality control, with a genotyping success rate of $100 \%$ and $100 \%$ reproducibility.

\section{Statistical analysis}

In order to simplify the analysis, genotypes were classified according to CPIC allele definition (42) and allele functionality tables, as the one described by our group for CYP1A2 (43). Thus, CYP2C19 genotypes were classified according to the number of functional alleles into IM-PM $\left({ }^{*} 1 /{ }^{*} 2, * 2 /{ }^{*} 2\right.$ and $\left.{ }^{*} 2 /{ }^{*} 17\right)$, NM $\left(* 1 /{ }^{*} 1\right)$, and UM (*1/*17 and *17/*17). Moreover, CYP2B6, CYP2C8 and CYP2C9 genotypes were also classified into PM (carriers of two mutated alleles), IM (carriers of CYP2B6*5 or *9, CYP $2 C 8 * 2, * 3$ or $* 4$ and CYP2C9*2 or *3 in heterozygosis), and NM (carriers of $* 1 /{ }^{*} 1$ genotype) according to the functionality of the alleles. CYP1A2*1C, *1, *1B and*1F were assigned an activity score of $0.5,1,1.25$ and 1.5, respectively. Thus, as previously validated (43), patients with $\operatorname{CYP} 1 A 2 * 1 /{ }^{*} 1 \mathrm{~B},{ }^{*} 1 /{ }^{*} 1 \mathrm{~F}$, $* 1 \mathrm{~B} /{ }^{*} 1 \mathrm{~B}, * 1 \mathrm{C} /{ }^{*} 1 \mathrm{~F}, * 1 \mathrm{C} /{ }^{*} 1 \mathrm{~B}$ genotypes were categorized into CYP1A2 NM/RM phenotype. Moreover, patients with $\mathrm{CYP} 1 \mathrm{A2} * 1 \mathrm{~B} /{ }^{*} 1 \mathrm{~F}$ and $* 1 \mathrm{~F} /{ }^{*} 1 \mathrm{~F}$ genotypes were assigned a UM phenotype. The only patient with $\operatorname{CYP} 1 A 2 * 1 C /{ }^{*} 1 \mathrm{C}$ genotype was classified as PM. Additionally, patients with CYP3A4 $* 1 /{ }^{*} 1$ were classified as NM and patients carrying the CYP3A4 $* 1 / * 22$ and $* 22 / * 22$ genotypes were classified as IM-PM. Likewise, patients with CYP3A5 $* 1 / * 3$ and $* 1 / * 6$ genotypes were classified as "expressers" and patients carrying 
CYP3A4 $* 3 / * 3$ and $* 3 / * 6$ genotype as "non-expressers". Regarding PON1, as there is no functionality table that allows inferring a phenotype, we assigned the NM phenotype to those patients without any mutation. On the contrary, carriers of one mutated allele in any of the three variants analyzed (rs662, rs854560 and rs705379) were considered IM. Patients carriers of two mutated alleles in any of the three PON1 variants were considered PM. Finally, ABCB1 C3435T, C1236T and G2677T/A genotypes were categorized into a haplotype "wild-type" when there was an absence of mutation, "heterozygote" when there was any heterozygous genotype in at least one of the three variants and "mutated" when there was two mutated alleles in any of the three polymorphisms.

For the analysis of the influence of all covariates, the aggregation value was translated into the variable "responders", which classified agregometry values equal or higher than 180 PRU into non-responders patients and values lower than 180 PRU into responder patients.

Statistical analysis was performed using the SPSS 22.0 software (SPSS Inc., Chicago, Illinois); we considered $\mathrm{p}$ values lower than 0.05 to be statistically significant. Differences in genotype frequencies according to sex and the comparison of the qualitative variables between different genotypes were determined using a corrected Pearson chi-square test. Differences in quantitative parameters between individuals were statistically analyzed by a parametric univariate analysis (t test or ANOVA) or non-parametric univariate analysis (Kruskal-Wallis). A multiple regression analysis was performed to analyze the effect on aggregation value and incidence of posterior ischemic and hemorrhagic events. For this purpose, categorical variables with more than two categories, such as phenotype, were analyzed using dummy variables. The time until the appearance of an ischemic or hemorrhagic event has been studied by means of the survival analysis with the Kaplan-Meier procedure, and the differences between the groups were evaluated via the Log-rank test with linear trend for factor levels. Patients were censored when either clopidogrel treatment or the follow-up was finished. 


\section{STUDY HIGHLIGHTS}

\section{What is the current knowledge on the topic?}

Although there is no standard guideline for clopidogrel treatment in patients with neurovascular conditions, the influence of CYP2C19 alleles on clopidogrel response is already confirmed.

\section{What question did this study address?}

This is the first study to carry out a joint analysis of CYP2C19 and other genes involved in clopidogrel treatment in patients subjected to percutaneous neurointervention.

\section{What does this study add to our knowledge?}

This study confirms that CYP2C19 is the most important enzyme involved in clopidogrel response. Indeed, CYP2C19 UM phenotype is a protective factor for the development of ischemic events, while it is a risk factor for bleeding complications. In addition, $A B C B 1$ is a key factor affecting clopidogrel distribution. Finally, the presence of CES1 G143E polymorphism might increase clopidogrel response, which needs to be confirmed.

\section{How this might change clinical pharmacology or translational science?}

We encourage considering an alternative antiplatelet therapy in CYP2C19 IM-PM and UM patients. Additionally, $A B C B 1$ polymorphisms could be considered for a better pharmacogenetic approach.

\section{ACKNOWLEDGMENTS}




\section{AUTHOR CONTRIBUTIONS}

M.S.R., C.B, D.K., P.Z. wrote the manuscript; J.L.C., E.B, D.O. and F.A.S designed the research; M.S.R, C.B., D.K, P.Z. and F.A.S. performed research, M.S.R. and D.R.P. analyzed the data; A.E. contributed with analytical tools. 
Table 1. Main demographic and clinical characteristics of the study population.

\begin{tabular}{|c|c|c|c|c|}
\hline & All $(\mathrm{N}=144)$ & Men $(n=74)$ & Women $(n=70)$ & P value \\
\hline Age (mean \pm SD) & $64.8 \pm 11.8$ & $67.5 \pm 11.5$ & $61.9 \pm 11.6$ & 0.004 \\
\hline Presence of cardiovascular risk factors & $129(89.6)$ & $70(94.6)$ & $59(84.3)$ & 0.056 \\
\hline Hypertension & $91(63.2)$ & $52(70.3)$ & $39(55.7)$ & 0.085 \\
\hline Dyslipidemia & $70(48.6)$ & $44(59.5)$ & $26(37.1)$ & 0.008 \\
\hline Obesity & $3(2.1)$ & $1(1.4)$ & $2(2.9)$ & 0.612 \\
\hline Atrial fibrillation & $3(2.1)$ & $3(4.1)$ & $0(0)$ & 0.245 \\
\hline Diabetes mellitus & $28(19.4)$ & $19(25.7)$ & $9(12.9)$ & 0.060 \\
\hline Currently smoking & $47(32.6)$ & $28(37.8)$ & $19(27.1)$ & 0.214 \\
\hline \multicolumn{5}{|l|}{ Previous ischemic and hemorrhagic events } \\
\hline Acute myocardial infarction & $9(6.3)$ & $8(10.8)$ & $1(1.4)$ & 0.034 \\
\hline Transient ischemic attack & $16(11.1)$ & $15(20.3)$ & $1(1.4)$ & $<0.001$ \\
\hline Ischemic stroke & 20 (13.9) & $14(18.9)$ & $6(8.6)$ & 0.093 \\
\hline Hemorrhagic stroke & $11(7.6)$ & $1(1.4)$ & $10(14.3)$ & 0.004 \\
\hline \multicolumn{5}{|l|}{ Reason for intervention } \\
\hline Aneurysms & $67(46.5)$ & $15(20.3)$ & $52(74.3)$ & $<0.001$ \\
\hline Stenosis & $77(53.5)$ & $59(79.7)$ & $18(25.7)$ & $<0.001$ \\
\hline \multicolumn{5}{|l|}{ Type of intervention } \\
\hline Flow diverter & $35(24.3)$ & $7(9.5)$ & $28(40.0)$ & \multirow{4}{*}{$<0.001$} \\
\hline Stent & $94(65.3)$ & $63(85.1)$ & $31(44.3)$ & \\
\hline Coil & $12(8.3)$ & $2(2.7)$ & $10(14.3)$ & \\
\hline No intervention & $3(2.1)$ & $2(2.7)$ & $1(1.4)$ & \\
\hline Patients with concomitant treatment & $141(97.9)$ & $73(98.6)$ & $68(97.1)$ & 0.612 \\
\hline OACs & $4(2.8)$ & $4(5.4)$ & $0(0)$ & 0.120 \\
\hline ASA & $139(96.5)$ & $73(98.6)$ & $66(94.3)$ & 0.200 \\
\hline Heparin & $1(0.7)$ & $1(1.4)$ & $0(0)$ & 1.000 \\
\hline NSAIDs & $7(4.9)$ & $2(2.7)$ & $5(7.1)$ & 0.266 \\
\hline PPIs & $110(76.4)$ & $56(75.7)$ & $54(77.1)$ & 0.847 \\
\hline SSRIs & $11(7.6)$ & $2(2.7)$ & $9(12.9)$ & 0.028 \\
\hline \multicolumn{5}{|l|}{ Patients outcome } \\
\hline Aggregation value, PRU ( $n=141)$ & $161.2 \pm 87.3$ & $173.8 \pm 86.0$ & $148.1 \pm 87.3$ & 0.081 \\
\hline Patients responding $(n=141)^{a}$ & $79(56.0)$ & $35(48.6)$ & $44(63.8)$ & 0.090 \\
\hline Patients requiring dose reduction & $7(4.9)$ & $1(1.4)$ & $6(8.6)$ & 0.058 \\
\hline Patients with change of treatment & $20(13.9)$ & $7(9.5)$ & $13(18.6)$ & 0.149 \\
\hline Appearance of subsequent ischemic event & $15(10.4)$ & $8(10.8)$ & $7(10.0)$ & 1.000 \\
\hline Appearance of subsequent hemorrhagic event & $12(8.3)$ & $7(9.5)$ & $5(7.1)$ & 0.766 \\
\hline
\end{tabular}

Values are presented as mean \pm SD or $n(\%)$ and median (range) for treatment duration. Abbreviation: OACs, oral anticoagulants; ASA, acetyl salicylic acid; NSAIDs, non-steroid anti-inflammatory drug; PPIs, proton-pump inhibitors; SSRIs, selective serotonin reuptake inhibitors; PRU, P2Y12 Reaction Unit. ${ }^{a}$ Patients were considered responders when PRU values were below 180. 
Table 2. Outcome of patients undergoing cerebral vascular intervention according to the studied genes.

\begin{tabular}{|c|c|c|c|c|c|}
\hline Gene & $\begin{array}{c}\text { Genotype/Phenotype/ } \\
\text { Haplotype }\end{array}$ & $\begin{array}{l}\text { Aggregation value, } \\
\text { PRU }(n=141)^{a, b}\end{array}$ & $\begin{array}{c}\text { Patients } \\
\text { responding }\end{array}$ & $\begin{array}{l}\text { Ischemic } \\
\text { events }\end{array}$ & $\begin{array}{l}\text { Hemorrhagic } \\
\text { events }\end{array}$ \\
\hline \multirow{4}{*}{ CYP2C19 } & PM-IM (n=37) & $200.1 \pm 84.3$ & $13(35.1)$ & $4(10.8)$ & $1(2.7)$ \\
\hline & NM $(n=63)$ & $140.3 \pm 89.2$ & $42(67.7)$ & $10(15.9)$ & $4(6.3)$ \\
\hline & UM $(n=44)$ & $157.9 \pm 76.8$ & $24(57.1)$ & $1(2.3)$ & $7(15.9)$ \\
\hline & $p$-value & 0.004 & 0.007 & 0.06 & 0.101 \\
\hline \multirow{3}{*}{ CYP2C9 } & PM-IM (n=69) & $153.7 \pm 85.9$ & $39(56.5)$ & 11 (15.9) & $4(5.8)$ \\
\hline & NM $(n=71)$ & $173.8 \pm 86.3$ & $36(52.9)$ & $4(5.6)$ & $8(11.3)$ \\
\hline & $\mathrm{p}$-value & 0.173 & 0.733 & 0.059 & 0.367 \\
\hline \multirow{3}{*}{ CYP2C8 } & PM-IM $(n=64)$ & $150.7 \pm 85.7$ & $38(59.4)$ & $10(15.6)$ & $5(7.8)$ \\
\hline & NM $(n=76)$ & $175.1 \pm 86.0$ & $37(50.7)$ & $5(6.6)$ & $7(9.2)$ \\
\hline & $p$-value & 0.100 & 0.390 & 0.104 & 1 \\
\hline \multirow{4}{*}{ CYP1A2 } & $P M(n=1)$ & 60 & $1(100)$ & $0(0.0)$ & $0(0.0)$ \\
\hline & $\mathrm{NM} / \mathrm{RM}(\mathrm{n}=70)$ & $157.2 \pm 86.0$ & $41(60.3)$ & $7(10.0)$ & $7(10.0)$ \\
\hline & UM $(n=69)$ & $171.7 \pm 86.5$ & $33(48.5)$ & $8(11.6)$ & $587.2)$ \\
\hline & $p$-value & 0.303 & 0.201 & 0.814 & 0.784 \\
\hline \multirow{4}{*}{ CYP2B6 } & $\mathrm{PM}(\mathrm{n}=17)$ & $170.1 \pm 65.3$ & $11(64.7)$ & $3(17.6)$ & $1(5.9)$ \\
\hline & $\mathrm{IM}(\mathrm{n}=61)$ & $153.1 \pm 82.9$ & 33 (56.9) & $7(11.5)$ & $4(6.6)$ \\
\hline & NM $(n=62)$ & $171.8 \pm 94.4$ & $31(50.0)$ & $5(8.1)$ & $7(11.3)$ \\
\hline & $p$-value & 0.474 & 0.518 & 0.508 & 0.641 \\
\hline \multirow{3}{*}{ CYP3A4 } & NM $(n=123)$ & $165.7 \pm 84.7$ & $64(52.9)$ & $12(9.8)$ & $9(7.3)$ \\
\hline & PM-IM $(n=17)$ & $148.7 \pm 99.1$ & $11(68.8)$ & $3(17.6)$ & $3(17.6)$ \\
\hline & $p$-value & 0.464 & 0.29 & 0.395 & 0.163 \\
\hline \multirow{3}{*}{ CYP3A5 } & Non-expressers $(n=123)$ & $179.6 \pm 73.6$ & $7(41.2)$ & $3(17.6)$ & $1(5.9)$ \\
\hline & Expressers $(n=17)$ & $161.4 \pm 88.1$ & $68(56.7)$ & $12(9.8)$ & $11(8.9)$ \\
\hline & $p$-value & 0.418 & 0.3 & 0.395 & 1 \\
\hline \multirow{3}{*}{$\begin{array}{c}\text { CES1 } \\
\text { rs71647871 }\end{array}$} & $C / C(n=138)$ & $165.2 \pm 86.0$ & $71(54.1)$ & $15(10.9)$ & $12(8.7)$ \\
\hline & $C / T(n=2)$ & $59.0 \pm 21.2$ & $2(100.0)$ & $0(0.0)$ & $0(0.0)$ \\
\hline & $p$-value & 0.084 & 0.501 & 1 & 1 \\
\hline \multirow{4}{*}{ PON1 } & $\mathrm{PM}(\mathrm{n}=114)$ & $165.3 \pm 86.6$ & $59(52.7)$ & $15(13.2)$ & $10(8.8)$ \\
\hline & IM (n=19) & $164.1 \pm 86.3$ & $11(57.9)$ & $0(0.0)$ & $1(5.3)$ \\
\hline & $\mathrm{NM}(n=7)$ & $130.2 \pm 90.6$ & $5(83.3)$ & $0(0.0)$ & $1(14.3)$ \\
\hline & $p$-value & 0.626 & 0.358 & 0.184 & 0.673 \\
\hline \multirow{4}{*}{ ABCB1 } & Wild-type $(n=30)$ & $168.7 \pm 87.0$ & $13(43.3)$ & $4(13.3)$ & $2(6.7)$ \\
\hline & Heterozygous $(n=83)$ & $165.7 \pm 88.5$ & $41(50.6)$ & $10(12.0)$ & $8(9.6)$ \\
\hline & Mutated $(n=27)$ & $151.7 \pm 80.9$ & $21(80.8)$ & $1(3.7)$ & $2(7.4)$ \\
\hline & $p$-value & 0.727 & 0.009 & 0.478 & 1 \\
\hline \multirow{3}{*}{ P2RY12 } & $\mathrm{H} 1(\mathrm{n}=103)$ & $167.2 \pm 86.6$ & $53(53.0)$ & $10(9.7)$ & $9(8.7)$ \\
\hline & $\mathrm{H} 2(\mathrm{n}=4)$ & $177.0 \pm 78.1$ & $2(50.0)$ & $0(0.0)$ & $0(0.0)$ \\
\hline & $p$-value & 0.825 & 1 & 1 & 1 \\
\hline
\end{tabular}

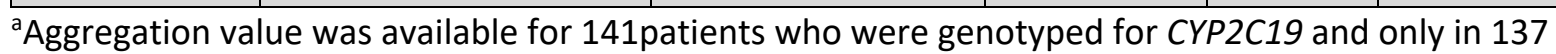
patients evaluated for the rest of the genes. Values are expressed as $n(\%)$ but ${ }^{b}$ mean \pm SD. ${ }^{c}$ Patients were considered responders when PRU values were below 180. 
Table 3. Results from the multivariate analysis

\begin{tabular}{|l|c|c|c|c|c|c|}
\hline \multicolumn{6}{|c|}{ Variables Contributing to P2Y12 Receptor Blockade (Aggregation value as dependent variable) } \\
\hline $\begin{array}{c}\text { Aggregation Value } \\
\text { Predictors }\end{array}$ & $\begin{array}{c}\text { Non- } \\
\text { standardized } \\
\beta \text { coefficient }\end{array}$ & $p$-value & $\begin{array}{c}\text { Semi-partial } \\
\text { correlation }\end{array}$ & $\begin{array}{c}\text { Contribution } \\
\text { to model } \\
\text { variance }\end{array}$ & $\begin{array}{c}\text { Additive } \\
\text { contribution to } \\
\text { model variance }\end{array}$ & $\begin{array}{c}\text { P2Y12 Receptor } \\
\text { Blockade }\end{array}$ \\
\hline Age & 2.235 & 0.001 & 0.288 & $8.2 \%$ & $8.2 \%$ & Worse response \\
\hline CYP2C19 IM-PM & 59.519 & $<0.001$ & 0.302 & $9.1 \%$ & $17.3 \%$ & Worse response \\
\hline Flow diverter & -52.848 & 0.004 & -0.243 & $5.9 \%$ & $23.2 \%$ & Better response \\
\hline PPIs treatment & 38.404 & 0.029 & 0.181 & $3.2 \%$ & $26.4 \%$ & Worse response \\
\hline \multicolumn{7}{|c|}{ Adjusted R-squared $=0.327$} \\
\hline
\end{tabular}

\begin{tabular}{|l|c|c|c|c|c|}
\hline \multicolumn{6}{|c|}{ Variables Contributing to P2Y12 Receptor Blockade (PRU>179 = Non-Responders) } \\
\hline $\begin{array}{l}\text { Response rate } \\
\text { predictors }\end{array}$ & Odds-Ratio & $\begin{array}{c}\text { Lower 95\% } \\
\mathrm{Cl}\end{array}$ & $\begin{array}{c}\text { Upper 95\% } \\
\mathrm{Cl}\end{array}$ & p-value & $\begin{array}{c}\text { P2Y12 Receptor } \\
\text { Blockade }\end{array}$ \\
\hline Age & 0.895 & 0.849 & 0.943 & $<0.001$ & Worse response \\
\hline CYP2C19 IM-PM & 0.149 & 0.045 & 0.498 & 0.002 & Worse response \\
\hline ABCB1 mutated & 6.298 & 1.555 & 25.499 & 0.010 & Better response \\
\hline \multicolumn{7}{|c|}{ R-squared=0.433 } \\
\hline
\end{tabular}

\begin{tabular}{|l|c|c|c|c|c|}
\hline \multicolumn{7}{|c|}{ Variables predicting the incidence of ischemic events } \\
\hline Ischemia Predictors & Odds-Ratio & $\begin{array}{c}\text { Lower } \\
95 \% \mathrm{Cl}\end{array}$ & $\begin{array}{c}\text { Upper } \\
95 \% \mathrm{Cl}\end{array}$ & $\mathrm{p}$-value & Variable \\
\hline CYP2C19 UM & 0.060 & 0.003 & 1.076 & 0.056 & Protective factor \\
\hline $\begin{array}{l}\text { Treatment duration } \\
\text { (months) }\end{array}$ & 1.041 & 1.007 & 1.077 & 0.017 & Risk predictor \\
\hline \multicolumn{7}{|c|}{ R-squared $=0.255$} \\
\hline
\end{tabular}

\begin{tabular}{|l|c|c|c|c|c|}
\hline \multicolumn{7}{|c|}{ Variables predicting the incidence of hemorrhagic events } \\
\hline $\begin{array}{l}\text { Hemorrhage } \\
\text { Predictors }\end{array}$ & Odds-Ratio & $\begin{array}{l}\text { Lower } \\
95 \% \mathrm{Cl}\end{array}$ & $\begin{array}{c}\text { Upper } \\
95 \% \mathrm{Cl}\end{array}$ & p-value & Variable \\
\hline CYP2C19 UM & 3.60 & 1.071 & 12.1 & 0,038 & Risk predictor \\
\hline \multicolumn{7}{|c|}{ R-squared= 0.070} \\
\hline
\end{tabular}




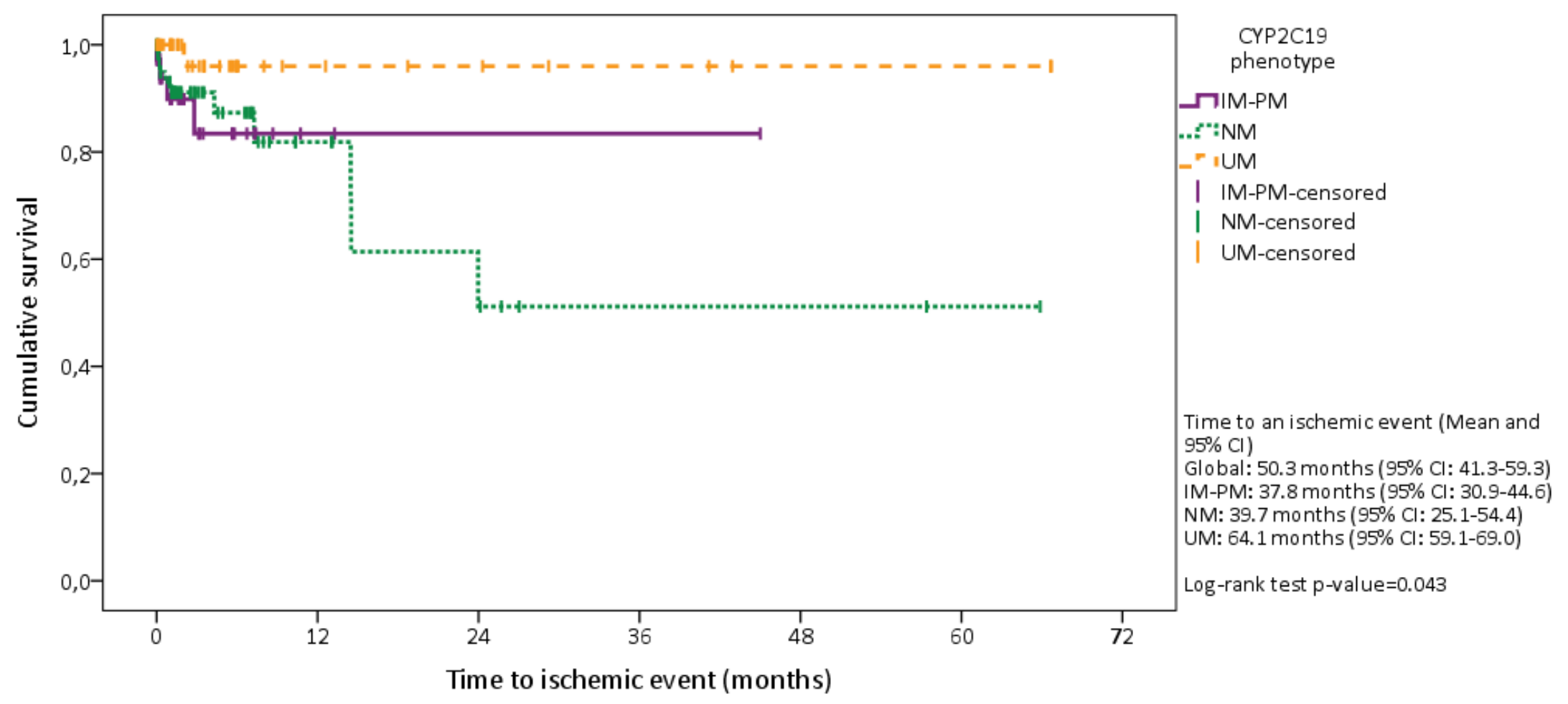

\begin{tabular}{|c|c|c|c|c|c|c|c|c|c|c|}
\hline & $\begin{array}{l}\text { Number of } \\
\text { patients at risk }\end{array}$ & Baseline & 1 month & 2 months & 3 months & 6 months & 12 months & 24 months & 48 months & 60 months \\
\hline \multirow{3}{*}{ 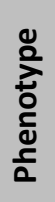 } & IM-PM & 37 & 23 & 16 & 13 & 7 & 2 & 1 & 0 & 0 \\
\hline & NM & 63 & 49 & 31 & 27 & 21 & 10 & 5 & 2 & 1 \\
\hline & UM & 44 & 36 & 25 & 22 & 13 & 9 & 7 & 1 & 1 \\
\hline
\end{tabular}

Figure 1a. The time until the appearance of an (a) ischemic or (b) hemorrhagic event studied by survival analysis with the Kaplan-Meier procedure. 


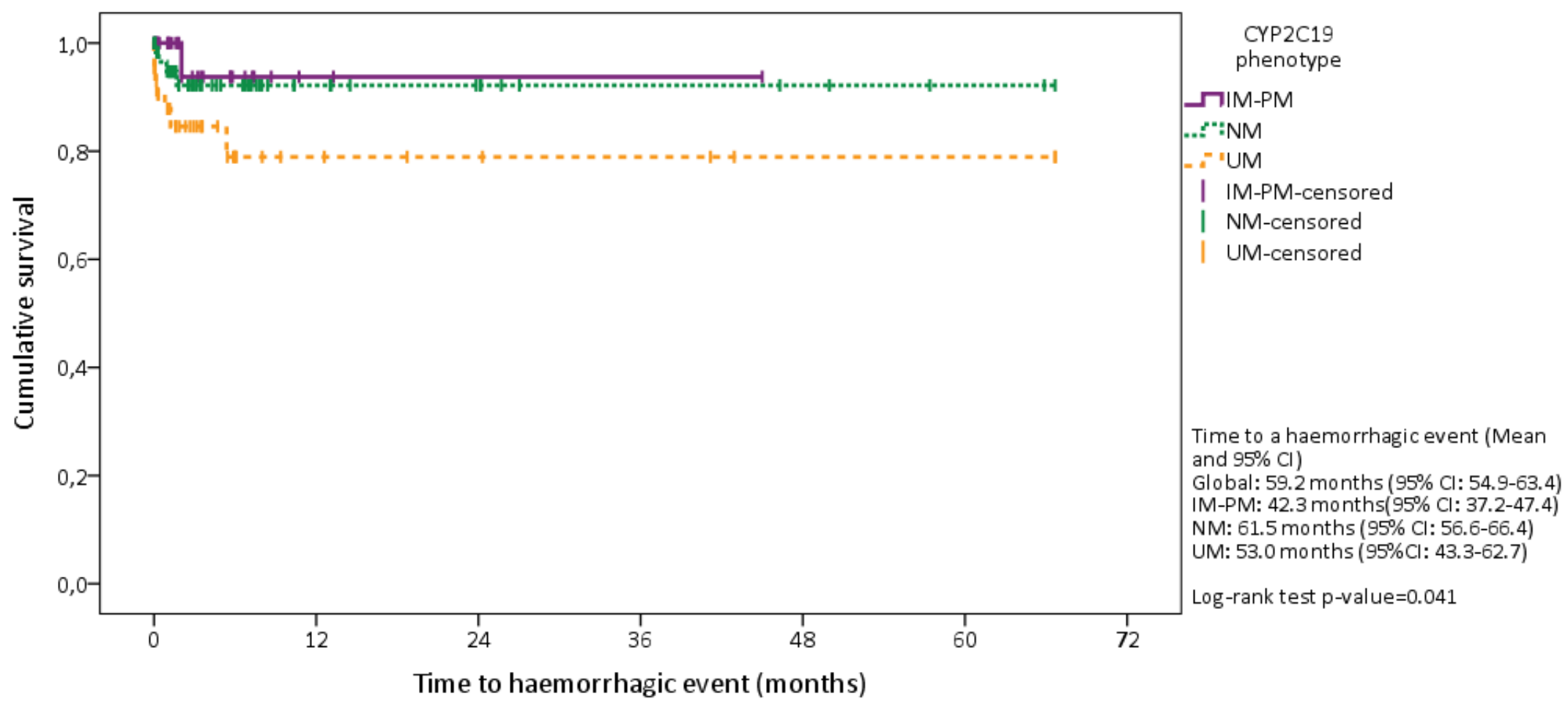

\begin{tabular}{|c|c|c|c|c|c|c|c|c|c|c|}
\cline { 2 - 11 } \multicolumn{1}{l|}{} & $\begin{array}{l}\text { Number of } \\
\text { patients at risk }\end{array}$ & Baseline & 1 month & 2 months & 3 months & $\mathbf{6}$ months & $\mathbf{1 2}$ months & 24 months & $\mathbf{4 8}$ months & $\mathbf{6 0}$ months \\
\hline IM-PM & 37 & 24 & 16 & 13 & 7 & 2 & 1 & 0 & 0 \\
\hline \multirow{2}{*}{} & NM & 63 & 52 & 34 & 30 & 24 & 13 & 9 & 4 & 2 \\
\hline \multirow{2}{*}{} & UM & 44 & 33 & 23 & 20 & 11 & 7 & 4 & 1 & 1 \\
\hline
\end{tabular}

Figure $1 \mathrm{~b}$. The time until the appearance of an (a) ischemic or (b) hemorrhagic event studied by survival analysis with the Kaplan-Meier procedure. 
Supplementary table 1.

\begin{tabular}{|c|c|c|c|c|c|c|c|}
\hline Gene & Variant & rs number & $\begin{array}{l}\text { Reference } \\
\text { allele }\end{array}$ & $\begin{array}{l}\text { Alternative } \\
\text { allele }\end{array}$ & MAF* & Consequence & $\begin{array}{l}\text { Genotyping } \\
\text { method }\end{array}$ \\
\hline \multirow[t]{4}{*}{ ABCB1 } & C3435T & rs1045642 & G & $A$ & 0.4 & Synonymous variant & MassArray \\
\hline & G2677T/A & rs2032582 & C & $A$ & 0.4 & Missense variant & MassArray \\
\hline & G2677T/A & rs2032582 & C & $\mathrm{T}$ & 0.05 & Missense variant & MassArray \\
\hline & C1236T & rs1128503 & G & $A$ & 0.4 & Synonymous variant & MassArray \\
\hline \multirow[t]{3}{*}{ CYP1A2 } & $* 1 \mathrm{C}$ & rs2069514 & $\bar{G}$ & $\bar{A}$ & 0.21 & Upstream gene variant & TaqMan \\
\hline & $* 1 \mathrm{~F}$ & rs762551 & $A$ & C & 0.37 & Intron variant & MassArray \\
\hline & $* 1 \mathrm{~B}$ & rs2470890 & $\mathrm{T}$ & C & (T) 0.24 & Synonymous variant & MassArray \\
\hline \multirow[t]{2}{*}{ CYP2B6 } & $* 9$ & rs3745274 & $\bar{G}$ & $\bar{T}$ & 0.32 & Missense variant & TaqMan \\
\hline & *5 & rs3211371 & C & $\mathrm{T}$ & 0.05 & Missense variant & MassArray \\
\hline \multirow[t]{3}{*}{ CYP2C8 } & $* 2$ & rs11572103 & $\bar{T}$ & $A$ & 0.05 & Missense variant & MassArray \\
\hline & *3 & rs10509681 & $\mathrm{T}$ & C & 0.05 & Missense variant & MassArray \\
\hline & $* 4$ & rs1058930 & G & $\mathrm{C}$ & 0.02 & Missense variant & MassArray \\
\hline \multirow[t]{2}{*}{ CYP2C9 } & $* 2$ & rs1799853 & C & $T$ & 0.05 & Missense variant & MassArray \\
\hline & *3 & rs1057910 & A & C & 0.05 & Missense variant & MassArray \\
\hline \multirow[t]{3}{*}{ CYP2C19 } & $* 2$ & rs4244285 & $\bar{G}$ & $A$ & 0.22 & Synonymous variant & LightMix \\
\hline & *3 & rs4986893 & G & A & 0.01 & Stop gained & LightMix \\
\hline & $* 17$ & rs12248560 & C & $\mathrm{T}$ & 0.15 & Intron variant & LightSNiP \\
\hline \multirow[t]{2}{*}{ CYP3A4 } & $* 20$ & rs67666821 & - & $T$ & $<0.001$ & Frameshift variant & MassArray \\
\hline & $* 22$ & rs35599367 & G & A & 0.09 & Intron variant & MassArray \\
\hline \multirow[t]{2}{*}{ CYP3A5 } & $* 3$ & rs776746 & $T$ & $\mathrm{C}$ & (T) 0.38 & Splice acceptor variant & MassArray \\
\hline & *6 & rs10264272 & C & $\mathrm{T}$ & 0.04 & Synonymous variant & MassArray \\
\hline \multirow[t]{3}{*}{ PON1 } & Q192R & rs662 & $\bar{T}$ & $\mathrm{C}$ & 0.46 & Missense variant & MassArray \\
\hline & L55M & rs854560 & A & $\mathrm{T}$ & 0.18 & Missense variant & MassArray \\
\hline & & rs705379 & G & A & 0.35 & Upstream gene variant & TaqMan \\
\hline CES1 & & rs71647871 & C & $\mathrm{T}$ & 0.04 & Missense variant & MassArray \\
\hline \multirow[t]{10}{*}{ P2RY12 } & & rs2046934 & G & A & (G) 0.13 & Intron variant & MassArray \\
\hline & & rs6798347 & G & A & 0.29 & Intron variant & MassArray \\
\hline & & rs6809699 & C & A & 0.09 & Synonymous variant & MassArray \\
\hline & & rs9859552 & G & $\mathrm{T}$ & 0.06 & Intron variant & MassArray \\
\hline & & rs16846673 & $\mathrm{T}$ & C & 0.02 & Missense variant & MassArray \\
\hline & & rs6785930 & G & A & 0.24 & Missense variant & MassArray \\
\hline & & rs10935838 & G & A & 0.13 & Intron variant & MassArray \\
\hline & & rs5853517 & - & $\mathrm{T}$ & 0.13 & Intron variant & MassArray \\
\hline & & rs6801273 & C & $\mathrm{T}$ & (C) 0.42 & Intron variant & MassArray \\
\hline & & rs6787801 & G & A & (G) 0.47 & Intron variant & MassArray \\
\hline
\end{tabular}

*Minor Allele Frequence (MAF) corresponds to the alternative allele, otherwise it is indicated in parentheses. 
Supplementary table 2. Genotypic frequencies of the studied genes.

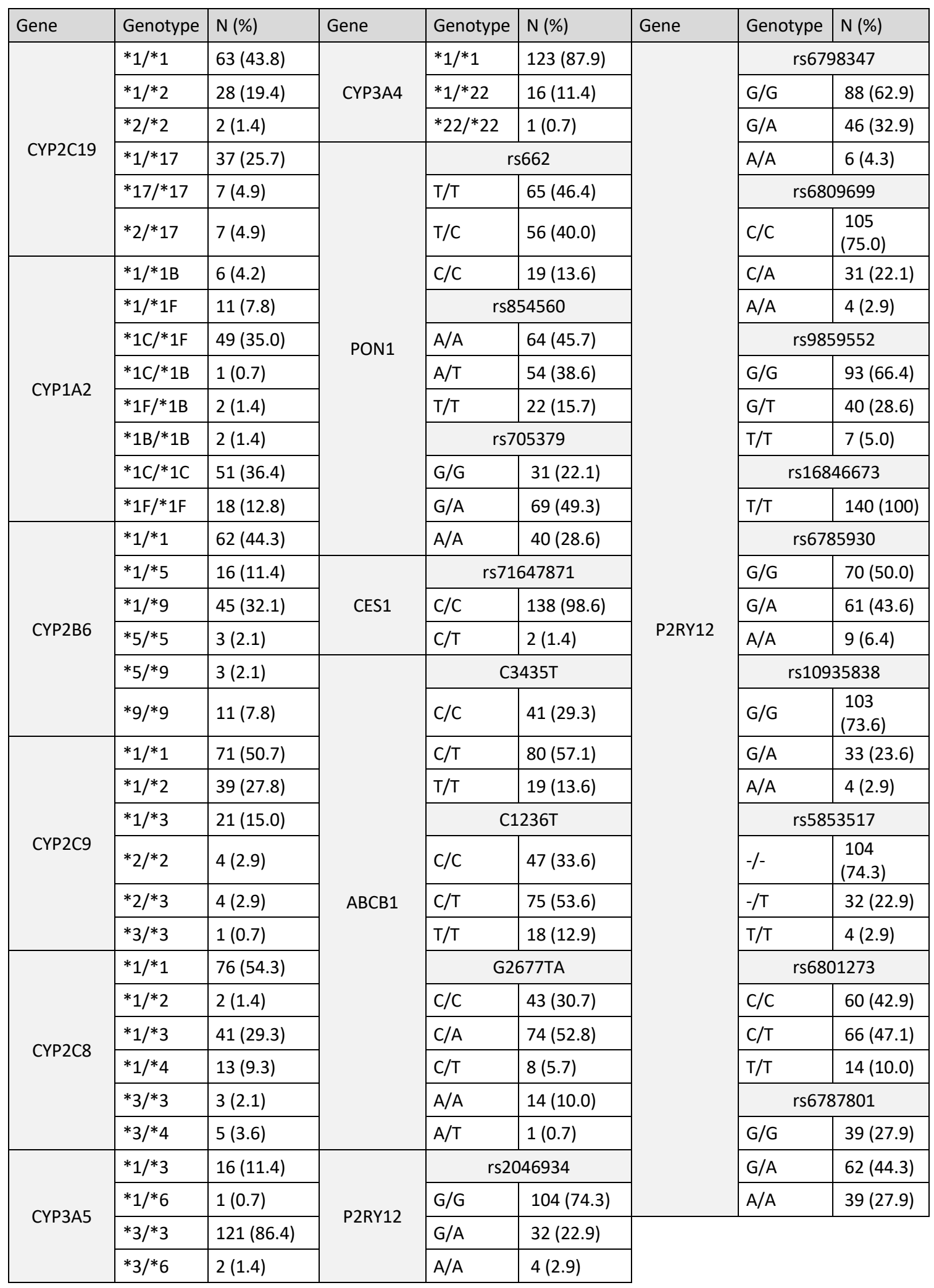




\section{References}

1. Colley R, Yan B. Genetic determinations of variable responsiveness to clopidogrel and implications for neurointerventional procedures. Interv Neurol. 2012 May;1(1):22-30.

2. Taubert D, von Beckerath N, Grimberg G, Lazar A, Jung N, Goeser T, et al. Impact of Pglycoprotein on clopidogrel absorption. Clin Pharmacol Ther. 2006 Nov;80(5):486-501.

3. Lins R, Broekhuysen J, Necciari J, Deroubaix X. Pharmacokinetic profile of 14C-labeled clopidogrel. Semin Thromb Hemost. 1999;25 Suppl 2:29-33.

4. Sangkuhl K, Klein TE, Altman RB. Clopidogrel pathway. Pharmacogenet Genomics. 2010 Jul;20(7):463-5.

5. Bouman HJ, Schömig E, van Werkum JW, Velder J, Hackeng CM, Hirschhäuser $\mathrm{C}$, et al. Paraoxonase-1 is a major determinant of clopidogrel efficacy. Nat Med. 2011 Jan;17(1):110-6.

6. Trenk D, Hochholzer W. Genetics of platelet inhibitor treatment. Br J Clin Pharmacol. 2014 Apr;77(4):642-53.

7. Savi P, Pereillo JM, Uzabiaga MF, Combalbert J, Picard C, Maffrand JP, et al. Identification and biological activity of the active metabolite of clopidogrel. Thromb Haemost. 2000 Nov;84(5):891-6.

8. Mega JL, Simon T, Collet J-P, Anderson JL, Antman EM, Bliden K, et al. Reduced-function CYP2C19 genotype and risk of adverse clinical outcomes among patients treated with clopidogrel predominantly for PCl: a meta-analysis. JAMA. 2010 Oct 27;304(16):1821-30.

9. Giusti B, Gori AM, Marcucci R, Saracini C, Sestini I, Paniccia R, et al. Cytochrome P450 2C19 lossof-function polymorphism, but not CYP3A4 IVS10 + 12G/A and P2Y12 T744C polymorphisms, is associated with response variability to dual antiplatelet treatment in high-risk vascular patients. Pharmacogenet Genomics. 2007 Dec;17(12):1057-64.

10. Zabalza M, Subirana I, Sala J, Lluis-Ganella C, Lucas G, Tomás M, et al. Meta-analyses of the association between cytochrome CYP2C19 loss- and gain-of-function polymorphisms and cardiovascular outcomes in patients with coronary artery disease treated with clopidogrel. Heart. 2012 Jan 15;98(2):100-8.

11. Sibbing D, Stegherr J, Latz W, Koch W, Mehilli J, Dörrler K, et al. Cytochrome P450 2C19 loss-offunction polymorphism and stent thrombosis following percutaneous coronary intervention. Eur Heart J. 2009 Apr;30(8):916-22.

12. Mega JL, Close SL, Wiviott SD, Shen L, Hockett RD, Brandt JT, et al. Cytochrome p-450 polymorphisms and response to clopidogrel. N Engl J Med. 2009 Jan 22;360(4):354-62.

13. Frére C, Cuisset T, Gaborit B, Alessi M-C, Hulot J-S. The CYP2C19*17 allele is associated with better platelet response to clopidogrel in patients admitted for non-ST acute coronary syndrome. J Thromb Haemost JTH. 2009 Aug;7(8):1409-11.

14. Sibbing D, Gebhard D, Koch W, Braun S, Stegherr J, Morath T, et al. Isolated and interactive impact of common CYP2C19 genetic variants on the antiplatelet effect of chronic clopidogrel therapy. J Thromb Haemost JTH. 2010 Aug;8(8):1685-93. 
15. Tiroch KA, Sibbing D, Koch W, Roosen-Runge T, Mehilli J, Schömig A, et al. Protective effect of the CYP2C19 *17 polymorphism with increased activation of clopidogrel on cardiovascular events. Am Heart J. 2010 Sep;160(3):506-12.

16. Sibbing D, Koch W, Gebhard D, Schuster T, Braun S, Stegherr J, et al. Cytochrome 2C19*17 allelic variant, platelet aggregation, bleeding events, and stent thrombosis in clopidogreltreated patients with coronary stent placement. Circulation. 2010 Feb 2;121(4):512-8.

17. Li Y, Tang H-L, Hu Y-F, Xie H-G. The gain-of-function variant allele CYP2C19*17: a double-edged sword between thrombosis and bleeding in clopidogrel-treated patients. J Thromb Haemost JTH. 2012 Feb;10(2):199-206.

18. Scott SA, Sangkuhl K, Stein CM, Hulot J-S, Mega JL, Roden DM, et al. Clinical Pharmacogenetics Implementation Consortium guidelines for CYP2C19 genotype and clopidogrel therapy: 2013 update. Clin Pharmacol Ther. 2013 Sep;94(3):317-23.

19. Saiz-Rodríguez M, Romero-Palacián D, Villalobos-Vilda C, Caniego JL, Belmonte C, Koller D, et al. Influence of CYP2C19 Phenotype on the Effect of Clopidogrel in Patients Undergoing a Percutaneous Neurointervention Procedure. Clin Pharmacol Ther. 2018 Mar 14;

20. Fitzgerald DJ, Maree A. Aspirin and clopidogrel resistance. Hematol Am Soc Hematol Educ Program. 2007;114-20.

21. Matetzky S, Shenkman B, Guetta V, Shechter M, Beinart R, Bienart R, et al. Clopidogrel resistance is associated with increased risk of recurrent atherothrombotic events in patients with acute myocardial infarction. Circulation. 2004 Jun 29;109(25):3171-5.

22. Shuldiner AR, O'Connell JR, Bliden KP, Gandhi A, Ryan K, Horenstein RB, et al. Association of cytochrome P450 2C19 genotype with the antiplatelet effect and clinical efficacy of clopidogrel therapy. JAMA. 2009 Aug 26;302(8):849-57.

23. Saiz-Rodríguez M, Belmonte C, Abad-Santos F. CYP2C19 Ultrarapid Phenotype as a Risk Predictor of Subsequent Events During Clopidogrel Treatment in Patients Undergoing a Percutaneous Neurointervention. Clin Pharmacol Ther [Internet]. 2019 Jan 16 [cited 2019 Jan 18]; Available from: http://doi.wiley.com/10.1002/cpt.1300

24. Lin M, Todaro M, Chan J, Churilov L, Zhu WS, Ramdave S, et al. Association between CYP2C19 Polymorphisms and Outcomes in Cerebral Endovascular Therapy. AJNR Am J Neuroradiol. 2016 Jan;37(1):108-13.

25. Zhu W-Y, Zhao T, Xiong X-Y, Li J, Wang L, Zhou Y, et al. Association of CYP2C19 Polymorphisms with the Clinical Efficacy of Clopidogrel Therapy in Patients Undergoing Carotid Artery Stenting in Asia. Sci Rep. 2016 03;6:25478.

26. Moore JM, Adeeb N, Shallwani H, Gupta R, Patel AS, Griessenauer CJ, et al. A Multicenter Cohort Comparison Study of the Safety, Efficacy, and Cost of Ticagrelor Compared to Clopidogrel in Aneurysm Flow Diverter Procedures. Neurosurgery. 2017 Oct 1;81(4):665-71.

27. Harmsze A, van Werkum JW, Bouman HJ, Ruven HJ, Breet NJ, Ten Berg JM, et al. Besides CYP2C19*2, the variant allele CYP2C9*3 is associated with higher on-clopidogrel platelet reactivity in patients on dual antiplatelet therapy undergoing elective coronary stent implantation. Pharmacogenet Genomics. 2010 Jan;20(1):18-25. 
28. Rytkin E, Mirzaev KB, Grishina EA, Smirnov VV, Ryzhikova KA, Sozaeva ZA, et al.

DoCYP2C19andABCB1gene polymorphisms and low CYP3A4 isoenzyme activity have an impact on stent implantation complications in acute coronary syndrome patients? Pharmacogenomics Pers Med. 2017;10:243-5.

29. Ford NF. The Metabolism of Clopidogrel: CYP2C19 Is a Minor Pathway. J Clin Pharmacol. 2016;56(12):1474-83.

30. Holmberg MT, Tornio A, Paile-Hyvärinen M, Tarkiainen EK, Neuvonen M, Neuvonen PJ, et al. CYP3A4*22 Impairs the Elimination of Ticagrelor, But Has No Significant Effect on the Bioactivation of Clopidogrel or Prasugrel. Clin Pharmacol Ther [Internet]. 2018 Aug 20 [cited 2018 Oct 31]; Available from: http://doi.wiley.com/10.1002/cpt.1177

31. Zhu H-J, Patrick KS, Yuan H-J, Wang J-S, Donovan JL, DeVane CL, et al. Two CES1 gene mutations lead to dysfunctional carboxylesterase 1 activity in man: clinical significance and molecular basis. Am J Hum Genet. 2008 Jun;82(6):1241-8.

32. Lewis JP, Horenstein RB, Ryan K, O'Connell JR, Gibson Q, Mitchell BD, et al. The functional G143E variant of carboxylesterase 1 is associated with increased clopidogrel active metabolite levels and greater clopidogrel response. Pharmacogenet Genomics. 2013 Jan;23(1):1-8.

33. Verschuren JJW, Boden $\mathrm{H}$, Wessels JAM, van der Hoeven BL, Trompet S, Heijmans BT, et al. Value of platelet pharmacogenetics in common clinical practice of patients with ST-segment elevation myocardial infarction. Int J Cardiol. 2013 Sep 10;167(6):2882-8.

34. Ameyaw MM, Regateiro F, Li T, Liu X, Tariq M, Mobarek A, et al. MDR1 pharmacogenetics: frequency of the C3435T mutation in exon 26 is significantly influenced by ethnicity. Pharmacogenetics. 2001 Apr;11(3):217-21.

35. Kim RB, Leake BF, Choo EF, Dresser GK, Kubba SV, Schwarz UI, et al. Identification of functionally variant MDR1 alleles among European Americans and African Americans. Clin Pharmacol Ther. 2001 Aug;70(2):189-99.

36. Sakaeda T, Nakamura T, Horinouchi M, Kakumoto M, Ohmoto N, Sakai T, et al. MDR1 genotyperelated pharmacokinetics of digoxin after single oral administration in healthy Japanese subjects. Pharm Res. 2001 Oct;18(10):1400-4.

37. Kurata $\mathrm{Y}$, leiri I, Kimura M, Morita T, Irie S, Urae A, et al. Role of human MDR1 gene polymorphism in bioavailability and interaction of digoxin, a substrate of P-glycoprotein. Clin Pharmacol Ther. 2002 Aug;72(2):209-19.

38. Szymezak J, Moreau C, Loriot M-A, Durand E, Van Viet H, Desnos M, et al. High on-clopidogrel platelet reactivity: genotyping can help to optimize antiplatelet treatment. Thromb Res. 2011 Jul;128(1):92-5.

39. Sridharan K, Kataria R, Tolani D, Bendkhale S, Gogtay NJ, Thatte UM. Evaluation of CYP2C19, $\mathrm{P} 2 \mathrm{Y} 12$, and $\mathrm{ABCB} 1$ polymorphisms and phenotypic response to clopidogrel in healthy Indian adults. Indian J Pharmacol. 2016 Aug;48(4):350-4.

40. Cuisset T, Frere C, Quilici J, Morange P-E, Saut N, Lambert M, et al. Role of the T744C polymorphism of the P2Y12 gene on platelet response to a 600-mg loading dose of clopidogrel in 597 patients with non-ST-segment elevation acute coronary syndrome. Thromb Res. 2007;120(6):893-9. 
41. Simon T, Verstuyft C, Mary-Krause M, Quteineh L, Drouet E, Méneveau N, et al. Genetic determinants of response to clopidogrel and cardiovascular events. N Engl J Med. 2009 Jan 22;360(4):363-75.

42. Caudle KE, Dunnenberger HM, Freimuth RR, Peterson JF, Burlison JD, Whirl-Carrillo M, et al. Standardizing terms for clinical pharmacogenetic test results: consensus terms from the Clinical Pharmacogenetics Implementation Consortium (CPIC). Genet Med Off J Am Coll Med Genet. 2017 Feb;19(2):215-23.

43. Saiz-Rodríguez $M$, Ochoa $D$, Belmonte $C$, Román $M$, Vieira de Lara $D$, Zubiaur $P$, et al. Polymorphisms in CYP1A2, CYP2C9 and ABCB1 affect agomelatine pharmacokinetics. J Psychopharmacol. 2019. [Accepted manuscript]. 